As a whole and as a reference book to the surgeon or general practitioner, it leaves little to be desired. To the student, several small paragraphs exhibit too much levity for a textbook supposed to be imparting exact information, e.g., on p. 36 "Though scopolamine is much used, I fear it. I have seen patients sleep too long; far too long." The reader is left guessing as to whether death has occurred or only a narcosis for a frightening length of time.

The anatomical nomenclature is mixed and apt to be confusing in parts. Instead of keeping to the now generally accepted Basle nomenclature we get on p. 69 when referring to the trigeminal or fifth cranial nerve, the hybrid term of 'trifacial' nerve. This is apt to be confused with the facial or seventh cranial nerve, and is altogether an undesirable name. On the following page the nerve is called by its correct name, the 'trigeminus.'

The proof-reading has been hurriedly and carelessly done and many inaccuracies were noted, e.g., on p. 132 we get "In cases where the breast tumour has been removed by paste"(!) The context suggests that 'in haste' was meant. At least half a dozen other similar mistakes were found.

On p. 269 a method is described for the resection of varicose veins and ulcers under local anæsthesia. This could well be omitted as most surgeons nowadays would never think of excising a varicose vein when the injection method is so eminently successful and easy, and when the vein injections have been done one usually finds that any varicose ulcers will heal by themselves.

In spite of these criticisms it is a good book and is deserving of less faded-looking gold lettering on the back.

\section{A. H. P.}

\section{MINOR SURGERY AND BANDAGING.-BY $G$. Williams, M.S., F.R.C.S. Twelfth Edition. London: J. \& A. Churchill, 1930 . Pp. vili plus 445, with 262 illustrations. Price, 10s. 6d. net.}

THE appearance of the twelfth edition of Minor Surgery and Bandaging by G. Williams is in itself an ample proof of the extensive demand for this instructive little book. It is the most useful book of its kind and because of its convenient size it can be easily carried in the pocket by senior students and house surgeons for ready reference. It is kept up to date with changes scattered throughout the book. Chapters on fractures have been extended and non-operative treatment of the commoner varieties of fractures has been detailed more fully with the help of illustrative diagrams. The injection treatment of varicose veins is well described and the chapter on anæsthetics revised. The book is nicely illustrated throughout and is strongly recommended for the use of students, house surgeons and general practitioners.

B. H. S.

INTERNATIONAL CLINICS. VOL. I. 40TH SERIES. -Edited by H. W. CattelI, A.M., M.D. London: J. B. Lipplncott Company, 1930. Pp. 309. Obtalnable from Butterworth and Co. (India), Ltd. Price, Rs. 37-8 per annum.

International Clinics, a quarterly of illustrated clinical lectures and specially prepared original articles on subjects of medical and surgical interest, has now reached its fortieth year of publication. The present volume contains sixteen original contributions; several of these fall within the domain of the specialist but the majority appeal directly to the general practitioner. In the latter group the articles by Brown of Baltimore, Colgan of Philadelphia and Dick of Chicago call for special mention.

The first-named author discusses the treatment of peptic ulcer in a refreshingly rational manner; his plea for a consideration of each case on its merits and for a cessation of the futile polemics of the protagonists of exclusively medical or exclusively surgical measures will not, it is hoped, fall on deaf ears. The diagnosis of incipient pulmonary tuberculosis is a problem which periodically engages the attention of every practising physician; Colgan's restatement of this problem is most timely. He emphasises the importance of apparently trivial abnormalities such as slight alterations in the breath sounds or slight differences in the relative expansion of the two sides of the chest-early signs too often missed by the physician. Finally we have a comprehensive survey by Dick of Chicago of his work on scarlet fever-a disease on which he is probably the greatest living authority. In the all-too-short space of twenty-six pages there is by far the best account of this subject that the reviewer has yet discovered. If other volumes of International Clinics are of equal excellence this is a publication which should find a place in the library of the specialist and of the general practitioner alike.

J. M. H.

PHYSIOLOGY AND BIOCHEMISTRY OF BACTERIA. VOLS. II \& III.-By R. E. Buchanan, Ph.D., and E. I. Fulmer, Ph.D. London: Ballilère, TIndall \& Cox, 1930. Pp. xvi plus 709, with 57 text-figures and $p p$. $x v$ plus 575, with 2 text-figures respectively. Price, 34s. net each.

These two volumes on the physiology and biochemistry of bacteria are in continuation of the first volume edited by R. E. Buchanan and E. I. Fulmer. Volume II deals with the effects of physical environment such as temperature, etc., and then the effects of chemical environment on these micro-organisms. There is an enormous amount of information on the subject, but it has been put together rather loosely. Volume III deals with the effects of these microorganisms on their environment. The majority of the changes are of a chemical nature due to various enzymes breaking up the different compounds in the substrate. The action of these organisms on the carbohydrates are dealt with in great detail, while those on the proteins and nitrogenous compounds contain very little information that is of practical use.

Chapter 14 considers the symbiotic relationship and inter-relationship of the enbacterales, and other microscopical organisms as well as the survival of these bacteria in molluses, insects, etc. These three volumes should be in the hands of every worker who is dealing with advanced bacteriology, as they contain an enormous amount of information on the physiology and biochemical changes produced by these organisms.

We should have liked to have seen the standard of Volume I kept up in Volumes II and III. but we realise the enormous field that these two authors have had to cover, and congratulate them on the result of their labours. The bibliography is very extensive, each of these volumes containing more than 120 pages of references.

H. W. A.

\section{CORRIGENDUM.}

ON page 467 of our issue for last August, we reviewed some recent publications by Sir Ronald Ross. As some of the books had no price mentioned, we presumed that they were for private circulation. We have since been informed by Sir Ronald that all the books concerned are for sale. They are published by Harrison \& Sons, London, and the following is the complete list:-

(i) Letters from Rome on Certain Discoveries connected with Malaria. Price, 7s. $6 d$.

(ii) Two Ross-Manson Letters (1897). Price, 5s.

(iii) Copies of Letters for Sir Patrick Manson (1899 and 1900) and General Gorgas (1914) to Sir Ronald Ross regarding his Discovery of the Connection between Malaria and certain Mosquitoes in 1897 to 1899. Price, 5s.

(iv) The Mode of Infection; three more RossManson Letters, 1898. Price, 5s.

(v) Memories of Sir Patrick Manson. Price, 10s, $6 d$. 